\title{
Cultura e política: A experiência dos coletivos de cultura no movimento estudantil
}

Culture and Politics: The Experience of Cultural Collectives within the Student Movement

Culture et politique : l'expérience des collectifs culturels dans le mouvement étudiant

\section{Marcos Ribeiro Mesquita}

\section{OpenEdition}

\section{Journals}

Edição electrónica

URL: http://journals.openedition.org/rccs/660

DOI: $10.4000 /$ rccs. 660

ISSN: 2182-7435

\section{Editora}

Centro de Estudos Sociais da Universidade de Coimbra

Edição impressa

Data de publição: 1 Junho 2008

Paginação: 179-207

ISSN: 0254-1106

Refêrencia eletrónica

Marcos Ribeiro Mesquita, «Cultura e política: A experiência dos coletivos de cultura no movimento estudantil », Revista Crítica de Ciências Sociais [Online], 81 | 2008, colocado online no dia 01 outubro 2012, criado a 01 maio 2019. URL : http://journals.openedition.org/rccs/660 ; DOI : 10.4000/rccs.660

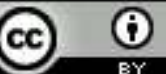




\title{
MARCOS RIBEIRO MESQUITA
}

\section{Cultura e política: \\ A experiência dos coletivos de cultura no movimento estudantil}

\begin{abstract}
A temática da juventude vem conquistando importante espaço e destaque nos últimos anos. Sua visibilidade, em grande medida retomada através da mídia e do mercado, é reforçada também pelo aparecimento do protagonismo de novos movimentos juvenis como os jovens da periferia, os militantes altermundistas, os jovens migrantes, entre outros que, num cenário recente, mostram sua vitalidade. Com o aparecimento destes novos atores ganham visibilidade também os movimentos juvenis clássicos, entre eles, o movimento estudantil, que volta à cena retomando seus antigos discursos sobre política e educação, mas que também se adapta às novas demandas estudantis e incorpora outras pautas ligadas aos campos da cultura e da identidade. Neste artigo, pretendemos analisar a participação de militantes estudantis em sua interface com a cultura de modo a compreender as implicações deste diálogo na rearticulação do próprio movimento junto aos jovens. Além disso se analisam também as repercussões que essa relação produz na identidade coletiva de um movimento social - em contínua construção - cada vez mais preocupado em diversificar seus discursos e práticas.
\end{abstract}

\section{Introdução}

O movimento estudantil brasileiro parece continuar num grande processo de experimentação. Como já discutido e analisado em outros trabalhos (Mesquita, 2001,2003, 2006) sua tentativa de se expressar através de outras vias, incorporando em seu interior temáticas transversais às tradicionalmente conhecidas, aos poucos, traz para si uma renovação em termos de forma e conteúdo que se notabiliza através de outras pautas e reivindicações, formas de atuação e espaços de participação.

Neste sentido, além de criar novos espaços de sociabilidade política, o movimento vem estabelecendo com os estudantes outros canais de comunicação, tão necessários, visto o desgaste de representação que atinge a maioria das entidades políticas, fruto da descrença social acerca da política institucional.

Junto à percepção deste desgaste, seguem as tentativas de resgate da representatividade e da força capaz de mobilizar. Desta forma, o movi- 
mento estudantil passa a acessar as experiências e repertórios do passado como espelhos para pensar o futuro e perceber, de modo particular, as novas demandas dos estudantes.

É este pêndulo da práxis e da identidade do movimento estudantil que queremos analisar neste trabalho: as diferentes formas de atuação que o movimento vem trilhando e construindo para recompor sua legitimidade frente aos estudantes. Em particular, analisaremos a intervenção deste movimento no âmbito da cultura. ${ }^{1}$

De fato, esta dimensão tem sido historicamente trabalhada pelo movimento estudantil de modo mais expressivo desde os anos $60 \mathrm{com}$ a experiência dos Centros Populares de Cultura (CPC). Atualmente, em outro contexto e com nova roupagem, essa atuação vem sendo retomada e estrategicamente utilizada como uma das formas de diversificar a identidade coletiva do movimento.

Se, por um lado, este continua mantendo sua identidade clássica/tradicional - seu habitus, visibilizado nas formas de atuação e linguagem próprias, característicos de um movimento institucionalizado -, por outro, recupera o desafio de se recriar a partir de outras lógicas de participação e intervenção política.

Como afirma Melucci (1999, 2001), os movimentos sociais não são um ente unitário, mas um conjunto de grupos que se articulam entre si, negociando idéias, representações, pautas e interesses que - em sua dinâmica interna - se processam e resultam em uma correspondente identidade coletiva. São, portanto, o resultado de processos de definições coletivas. É nesta perspectiva que consideramos e percebemos o surgimento de outras demandas e formas de atuação dentro do movimento estudantil, entre elas, aquela ligada à dimensão da cultura.

É a partir da interconexão dos diferentes grupos e redes existentes dentro do movimento que se gestam novas demandas e pautas, novos interesses e reivindicações, possibilitando uma dinâmica de permanente transformação da identidade coletiva. Antes, porém, de iniciarmos nossa análise sobre a atuação do movimento estudantil brasileiro no campo cultural, faremos uma breve reflexão sobre o estudo dos movimentos sociais e definiremos a perspectiva por nós adotada, uma questão essencial para deixar claro de que lugar falamos.

\footnotetext{
${ }^{1}$ Neste trabalho, analisaremos os coletivos de cultura, com sua lógica diferenciada de militância, a partir da análise da $4^{a}$ Bienal de Arte e Cultura da União Nacional dos Estudantes (UNE) realizada nos dias de 25/02 a 02/03 de 2005 em São Paulo.
} 


\section{Movimentos sociais: definição, desconstrução e reconstrução à luz das práticas estudantis}

A temática dos movimentos sociais como categoria analítica e campo de investigação tem sido uma das mais discutidas e desenvolvidas nas ciências sociais. Seu dinamismo, conquistado com as diversas teorias que lhe conferiram destaque, fortaleceu essa área de forma a ser considerada o objeto central de análise da sociologia (Touraine, 1999).

No Brasil, a produção relativa a este tema tem tido uma grande vitalidade, abordando diferentes aspectos e os mais diversificados atores sociais. Porém, tem se caracterizado, ainda que de forma não rígida, por uma divisão dos estudos nas áreas acadêmicas. A antropologia trabalhando as questões indígenas; a política e a sociologia urbana discutindo acerca dos movimentos sociais e populares; o direito e a arquitetura ligados às pesquisas relativas à moradia e terra; entre outros (Gohn, 1997).

Mas, se o tema ganhou um caráter de tamanha importância, ao mesmo tempo, tornou-se mais complexo e produziu um campo onde "tudo cabe", e portanto, mais difícil de conceituar e teorizar.

As dificuldades de conceituação são inúmeras. Uma delas é a tendência a uma percepção estanque dos movimentos sociais como objetos de análise, muitas vezes naturalizados e observados de modo homogêneo, não considerando as nuances de sua dinamicidade interna. Além disso, as dificuldades de diferenciá-los de outros fenômenos sociais como as ações coletivas de protesto, por exemplo.

Estas dificuldades, em certa medida, estão relacionadas com a forma pela qual fomos habituados a pensar, compreender e estudar a realidade social enquanto temática de interesse e investigação. O uso de "óculos" rígidos e estáticos, a recorrência na percepção e na realização de pesquisas que levam em conta apenas a estrutura organizativa e aquilo que é visível em termos de participação, a escassez de instrumentos teórico-metodológicos que possibilitem observar a dinamicidade e riqueza constituinte da realidade, entre outros, são algumas das limitações existentes no estudo dos movimentos sociais.

Uma outra limitação acerca do estudo dos movimentos sociais se refere à própria perspectiva adotada pelos estudiosos. Nesse sentido, o significado do conceito de movimento social tem estado tradicionalmente fundado em uma concepção historicista, linear e objetivista da ação coletiva como indica Melucci (1996). Esta perspectiva está fortemente relacionada a uma compreensão largamente produzida e reproduzida no meio acadêmico e entre os formadores de opinião, qual seja, a naturalização dos movimentos sociais como sujeitos portadores de uma ação coletiva 
emancipadora. Isto não só dificulta como reifica a própria condição processual e dinâmica que caracteriza estes movimentos. Ainda como afirma Melucci, devemos abandonar a imagem moderna dos movimentos sociais observados como "sujeitos dotados de existência e intencionalidade que atuam num cenário cujo final está pré-determinado” (1989: 18).

Por estas e outras dificuldades relativas à teorização no campo dos movimentos sociais, Laraña (1999) sugere uma desconstrução e reconstrução teórica do conceito. Para este autor, os enfoques tradicionais não resultam muito úteis para compreender a dinamicidade e as profundas mudanças ocorridas na sociedade. Transformar a perspectiva e o enfoque do estudo dos movimentos sociais é, entre outras coisas, desconstruir e reconstruir a forma como ele é analisado e estudado.

Para diferentes autores (Laraña, 1999; Melucci, 1999, 2001), o movimento social não constitui uma entidade cujos elementos estão vinculados por lógicas externas, senão uma variedade de processos, atores sociais e estratégias de ação. Ou seja, os movimentos não são um "dado empírico unificado", mas antes, uma pluralidade de grupos que negociam, trocam e decidem internamente, derivando daí uma identidade coletiva. A unidade do movimento social não é um dado primeiro, inicial, uma condição prévia à existência do próprio movimento, senão uma consequência, um produto destas trocas.

Como sugere Melucci,

uma ação coletiva não pode ser explicada sem tomar em conta como são mobilizados os recursos internos e externos, como as estruturas organizativas são erigidas e mantidas, como as funções de liderança são garantidas. O que empiricamente denomina-se de 'movimento social' é um sistema de ação que conecta orientações e propósitos plurais. (1999: 38)

Laraña (1999: 198) também chama a atenção para o fato de que os estudos acerca dos movimentos sociais centram-se nas suas fases visíveis de mobilização, tendência que dá prioridade ao significado político frente à sua significação cultural.

Nesse sentido, faz-se importante para uma compreensão mais ampla dos processos que se desenvolvem em um movimento social analisar e perceber as redes submersas que dão sustentabilidade e continuidade ao mesmo. A percepção daquilo que é latente, informal e invisível na dinâmica dos movimentos sociais deve ser considerada como um elemento fundamental para compreender seus processos de mudança, estratégias de ação e valores. 
Novamente, é Melucci (1999) que abordará esta questão de maneira mais enfática. Esse autor sugere que, se os aspectos mais visíveis dos fenômenos coletivos existem, isso se deve, em grande medida, pela realização de um processo que se opera no seio do movimento social que é de contínua atividade e muitas vezes invisível para quem está de fora. São as experiências realizadas no cotidiano, a relação e interlocução estabelecida com outros grupos que possibilitarão a existência de uma latência que num dado momento ou contexto favorável se manifesta.

Além da ênfase às fases visíveis dos movimentos sociais, a tradição teórica, até pouco tempo atrás, centrava-se na perspectiva estrutural e organizativa dos mesmos, considerando muito mais as questões de fundo macro-social. McAdam, ao fazer uma defesa dos elementos culturais e cognitivos como importantes aspectos a serem considerados nestas investigações, afirma que "se o estudo dos movimentos sociais tem sido um dos campos intelectualmente mais produtivos e ativos da sociologia, também, como sucede com todos os paradigmas em formação, tem ressaltado certos aspectos do fenômeno e ignorado outros" (1994: 43).

Podemos afirmar que tradicionalmente o enfoque dado aos estudos dos processos de mobilização coletiva e da participação social tem tido um caráter macro-estrutural, desde as perspectivas mais clássicas às mais contemporâneas (Gohn, 1997). Do paradigma marxista - e sua centralidade na categoria de classe social - ao enfoque da mobilização de recursos - que aborda os movimentos sociais como grupos de interesses - todos eles enfatizam os elementos relativos às questões de cunho mais estrutural.

Numa perspectiva diferente, Jeffrey Alexander (1987) defende a necessidade de superar a divisão macro-micro no interior da sociologia. Em seu conhecido artigo denominado "O novo movimento teórico", o autor demarca sua posição pela estruturação de uma base teórica-metodológica que contemple as diferentes dimensões que a complexidade do tema exige.

Klandermans (1994), de outra forma, retoma a discussão acerca da necessidade de trabalhar estas duas dimensões de modo integrado e o faz a partir da divisão entre as duas perspectivas teóricas recentes mais importantes no campo do estudo dos movimentos sociais, a saber, a mobilização de recursos e os novos movimentos sociais.

Em artigo intitulado "La construcción social de la protesta y los campos pluriorganizativos”, Klandermans reforça a idéia de Alexander quando, ao comparar as duas perspectivas teóricas, nos remete à compreensão e necessidade de articulá-las de forma a complementarem-se. 
Para o autor, ambas, a primeira (baseada numa visão mais macro-estrutural) e a segunda (baseada numa visão mais micro-estrutural),

poderiam ser complementadas mutuamente se não compartilhassem uma importante debilidade. Nenhuma das duas explica o que faz com que as pessoas definam sua situação de tal maneira que a participação em um movimento social lhes pareça o mais apropriado. O enfoque dos novos movimentos sociais tratou de descobrir as origens das "demandas" dos movimentos sociais durante as duas últimas décadas, mas não chegou a dar-se conta de que a mudança estrutural não gera automaticamente movimentos sociais. Ao mesmo tempo, a perspectiva da mobilização de recursos investigou a "oferta" de organizações de movimentos sociais, mas passou por alto o fato de que só a presença destas não produz reivindicações, nem tampouco conduz a gente a participar ativamente nos movimentos. (Klandermans, 1994: 184)

Mas ainda no campo da conceituação dos movimentos sociais, quais as características que diferenciam estes de outros fenômenos marcados pela coletividade? As distinções entre os movimentos sociais e outras formas de ação coletiva podem ser realizadas levando em conta alguns eixos e características centrais, a saber: a) sua continuidade; b) visão de injustiça; c) relações com processos de mudança social; d) identidade coletiva.

Certamente, um movimento social se caracteriza por certo grau de continuidade na atividade que desenvolve, diferentemente de outras formas de ação coletiva marcadas pela espontaneidade e efemeridade, como as manifestações de protesto. Para Laraña (1999), a continuidade dos movimentos sociais é um dos eixos centrais que o movimento tem para realizar seus objetivos, sua estratégia e organização, sua liderança e estrutura de papéis, sua identidade coletiva. A ação coletiva exige uma continuidade do movimento para que os objetivos de mudança social levantados pelos mesmos sejam, de alguma forma, concretizados.

Não dado de maneira isolada, mas inserindo-o com as outras características, a noção de injustiça é um outro elemento que concorre para que os participantes de um dado movimento social se organizem e se estruturem enquanto tal para levar a cabo seus objetivos. A noção de injustiça é importante não apenas como elemento gerador de uma identidade coletiva mas também como um critério para a mobilização com fins a uma mudança social. ${ }^{2}$

\footnotetext{
${ }^{2} \mathrm{Na}$ Psicologia Social este tema foi - e continua sendo - tratado por diversos autores que a partir da categoria da "Crença no Mundo Justo", desenvolveram variadas pesquisas neste campo. Além disso, Sandoval (2001) em suas investigações acerca da consciência política coloca o binômio justiça/injustiça como uma das categorias centrais em seu modelo teórico.
} 
A mudança social está relacionada à perspectiva de ruptura com os limites do sistema que, para Melucci (1999), é um fator essencial na conceituação de um movimento e na diferenciação deste de outros fenômenos coletivos. Na elaboração de critérios para conceituar o movimento social, a mudança social é um dos critérios citados desde os primeiros trabalhos realizados neste campo.

Por fim, consideramos a existência de uma identidade coletiva, um dos elementos caracterizadores da constituição de um movimento social. Servindo como um fator de coesão grupal, a identidade está sempre em processo de transformação, visto a grande rapidez em que os movimentos sociais definem e redefinem seus objetivos e estratégias de ação.

A partir desta breve caracterização acerca dos elementos que constituem um movimento social, assumimos a conceituação definida por Melucci que o define como uma forma de ação coletiva que a) explicita um conflito social; b) apela à solidariedade e c) rompe os limites do sistema em que se produz.

Tentando contrapor a idéia de movimento social percebido como uma expressão e resposta frente a uma crise e, portanto, visto em geral como uma patologia social, Melucci (2001) sugere a explicitação do conflito social como um elemento que demarca uma percepção de luta entre dois atores pela apropriação de recursos valorizados por ambos.

Para esse autor, "não se trata de uma distinção de pouca importância, se é verdade que os grupos dominantes tendem a definir os movimentos como simples respostas a uma crise. Admitir que sejam algo diferente seria reconhecer a existência de questões coletivas que atingem a legitimidade do poder e o uso de recursos sociais" (Melucci, 2001: 34-35).

A idéia do apelo à solidariedade está intimamente relacionada à questão do reconhecimento e da identidade coletiva de seus participantes, sendo esta, portanto, a capacidade dos atores em se reconhecerem e serem reconhecidos como parte da mesma unidade social.

Por fim, o terceiro elemento que caracteriza e dá sustentabilidade ao conceito: a ruptura aos limites do sistema. Se o movimento social é a expressão de um conflito social isso acontece porque em sua base existem motivações de mudanças estruturais na sociedade em que ele está inserido.

Certamente, o surgimento dos novos movimentos sociais com suas demandas e reivindicações em meados dos anos 1960, ajudaram na reelaboração/redefinição do conceito, bem como, na maneira de "apreender" e analisar os objetos de análise. Os novos movimentos sociais não só exi- 
giram dos estudiosos uma reformulação teórica, mas também uma crítica aos instrumentos e métodos de investigação e a criação de novas metodologias que dessem conta da dinamicidade intrínseca a estes.

Esta dinamicidade é percebida não só através da temporalidade em que dadas mudanças ocorrem em um determinado movimento social (e que interferem, por exemplo, na processual identidade coletiva de seus membros), mas também pela própria estrutura organizacional que estes trazem como forma de manifestos.

Como sugere Laraña, "as estruturas deixam de ser um instrumento para realizar suas metas e passam a ser metas em si mesmas" (1999: 90). Ou seja, a forma deixa de ser apenas forma e se transforma em conteúdo antecipando aquilo que o movimento deseja expressar. A forma transforma-se em linguagem, expressa mensagens, comunica, visto que traz impresso em sua estrutura um número significativo de símbolos.

É a isto que Melucci se refere quando compreende os movimentos sociais como sistemas de ação e mensagens simbólicas. As estruturas e formas organizativas dos movimentos não se resumem a seus aspectos formais, visíveis, observáveis, e portanto, devem ser consideradas também as formas pelas quais estas mesmas estruturas se "estruturam". Em outras palavras, deve ser levada em consideração a dinâmica de negociação e conflito que se estabelece entre os membros de um movimento, no sentido de conseguirem conceber a estrutura organizativa que reflita seus ideários e que seja mais apropriada para a concretização de suas ações.

$\mathrm{Na}$ teoria da ação coletiva de Melucci, um ponto de destaque - e central nos processos que permitem a construção das identidades num determinado movimento - é a existência das redes sociais submersas. ${ }^{3}$ É neste campo, onde as diferentes redes dialogam e se inter-cruzam, que se gestam, se experienciam e se constroem as identidades coletivas.

Verdadeiros "laboratórios culturais" e espaços de ampla troca de experiências, estas redes sociais tomam diferentes formatos e se constituem na base da dinâmica do cotidiano, se realizando, quase sempre, no nível da invisibilidade e da transitoriedade, devido à rapidez com que se transformam os contextos e campos políticos.

\footnotetext{
${ }_{3}^{3}$ Num mesmo sentido, como lembram Johnston, Laraña e Gusfield (1994: 28), ao propor o termo catnet (fusão dos termos categoria e redes) para aludir a relação existente entre uma categoria social e uma identidade coletiva, Tilly também seria um dos autores que compartilha com a perspectiva da importância das redes no processo de construção de identidades coletivas. O mesmo "se referia também às redes sociais como a base estrutural necessária para que a primeira produza a segunda. Estas redes estão na maior parte das vezes submersas na vida cotidiana, mas se fazem visíveis quando se produzem mobilizações."
} 
Mas se estas redes se dão num nível micro da ação dos movimentos, em seu âmbito privado, as mesmas ganham visibilidade e força quando os atores coletivos se enfrentam ou entram em conflito no espaço político e público da sociedade. E é nesse continuum fronteiriço que se estabelece entre latência e visibilidade das redes sociais que as identidades coletivas são gestadas e fortalecidas.

É esta perspectiva teórica acerca da identidade coletiva abordada por Melucci (recuperada em muito da tradição do interacionismo simbólico) que iremos ter como base e suporte para nossas análises. A idéia de identidade coletiva continuamente negociada a partir das relações estabelecidas e concretas de determinado campo político é central na compreensão dos atuais movimentos sociais que atuam num ritmo cada vez acelerado.

Certamente esta velocidade está relacionada com uma maior criação de oportunidades políticas, gestadas tanto a partir do aumento no número de interlocução entre as diversas redes sociais organizadas na sociedade civil como do aumento da informação possibilitada pelo surgimento das novas tecnologias.

E aqui, retomamos a idéia de Melucci acerca da necessidade de desnaturalizar uma tendência hegemônica existente tanto no senso comum, quanto em muitas análises correntes sobre os fenômenos contemporâneos de ação coletiva que é a idéia de unicidade dos movimentos sociais.

Para este, "tende-se muitas vezes a representar os movimentos como personagens, com uma estrutura definida e homogênea, enquanto, na grande parte dos casos, trata-se de fenômenos heterogêneos e fragmentados, que devem destinar muitos dos seus recursos para gerir a complexidade e a diferenciação que os constitui" (Melucci, 2001: 29).

É nessa perspectiva que iremos estudar a ação do movimento estudantil no campo da cultura: com um olhar de quem percebe a movimentação dos diferentes grupos dentro do movimento de forma a possibilitar a existência de novas experiências no campo da militância política; com um olhar de quem observa a dinâmica que se estabelece entre os diferentes grupos para tentar conectar as dimensões da política e da cultura.

\section{Estudantes e cultura: resgatando o político que existe na contestação cultural}

A cultura, certamente, tem sido, nos últimos anos, uma das dimensões priorizadas pelo movimento estudantil como uma nova forma de fazer coletivo. Inicialmente, com o objetivo de atrair as forças estudantis dispersas para a participação no movimento, a União Nacional dos Estudantes (UNE) 
passou a incorporar esta temática a partir da realização das Bienais de Arte e Cultura.

Com esta experiência, o movimento tenta recuperar uma dimensão historicamente tradicional em sua trajetória. Ora de modo mais sistemático, ora menos prioritário enquanto forma política de atuação, a temática cultural sempre esteve presente na história do movimento estudantil brasileiro, tendo como experiência marcante a realização dos Centros Populares de Cultura (CPCs) nos anos $60,{ }^{4}$

A experiência da Bienal de Arte e Cultura da UNE, iniciada em 1999, surge como principal evento-marca nesta tentativa de restabelecer, no interior do movimento, e com nova roupagem, a ligação entre arte e política, cultura e participação. Na sua quarta edição (Salvador, 1999; Rio de Janeiro, 2001; Recife, 2003; São Paulo, 2005), a Bienal se fortalece enquanto um espaço-prisma, onde a produção cultural de estudantes e artistas é visibilizada e discutida.

A circulação e o intercâmbio de experiências das mais diversas expressões artísticas (cinema e vídeo, música, dança, literatura, teatro, etc.) realçam a importância do evento pelas suas dimensões. Além disso, se propõe ser um espaço de crítica à massificação da cultura - imposta pelo mercado globalizado - e à falta de investimentos na área cultural por parte do governo.

O mercado cultural é denunciado. ${ }^{5} \mathrm{Na}$ crítica ao modelo, a proposição de uma alternativa baseada na concepção de uma cultura enraizada

\footnotetext{
${ }^{4}$ Os CPCs surgiram na década de 60 numa articulação do movimento estudantil com movimentos artísticos-culturais. Sua principal função era, através da arte, politizar os trabalhadores e a sociedade em geral. Com o apoio do governo popular de João Goulart, esta experiência se multiplicou em vários lugares do país, e teve como ponto-chave a crítica social e a mobilização para a realização de uma Reforma Universitária. Para Ridenti (2000), talvez não tenha havido um momento da história recente mais marcado pela convergência entre política, cultura, vida pública e privada que os anos 60 e esta convergência de possibilidades de mudança certamente influenciou no contexto de organização e surgimento dos CPCs. Trabalhando com a categoria proposta por Löwy e Sayre (1995), intitulada de romantismo revolucionário, o autor analisa a prática de militantes intelectuais e artistas desta década. Para ele, é o conteúdo e ideário implícitos nesta categoria que - compartilhada por um expressivo número de militantes - vai dinamitar uma série de experiências culturais de caráter político.

${ }^{5}$ Cf. o lançamento da $2^{a}$ Bienal de Arte e Cultura da UNE:

"Mãos que vão tirar cada tijolo da cela do silêncio e romper os muros da prisão em que se transformou a indústria cultural. Luzes acesas em meio à escuridão deste final de milênio. Água que jorra das minas numa época de torneiras secas. Chaves para abrir as portas da participação. Arte não é remédio falso. Jovem não é otário. Trabalhador não é lixo. Por isso o Circuito está no centro de um cruzamento que vai ligar o artista, o público, o patrocinador, a arte, o indivíduo e o coletivo. Ela vai no fundo, do fundo, do fundo, se for para trazer o diamante de diferença, da independência e da mudança. Afinal produtor cultural não tem que se resignar com papel de cão de guarda do neoliberalismo. Como orvalho não enche o poço, a UNE estará provocando uma chuva de esperança que fará brotar a semente da transformação. Um terremoto cultural que abalará os ali-
} 
nos problemas e na vida do país e na valorização da cultura popular. Os estudantes propõem a redescoberta do país e de suas origens através da cultura. Neste sentido, são emblemáticos os temas centrais das Bienais de Recife e São Paulo, a saber, "Um encontro com a cultura popular" e "Encontro com nossa América", respectivamente.

Como relata um dos militantes que participa de um dos coletivos de cultura sobre a tematização da cultura popular na III Bienal realizada em Recife,

A gente achou que era importante começar a discutir a identidade cultural; porque a gente acha que é uma forma de se contrapor à massificação, à globalização, tudo o que vem meio enlatado pra gente. Seria um caminho pra gente buscar as raízes, não de uma maneira conservadora, entendendo que tudo isso se mistura, que arte é uma mistura de várias coisas, inclusive do que tem de cultura popular, de arte popular. E se voltar, voltar o olhar pra arte popular é uma forma de você compreender o nosso povo, compreender o que a gente tem de original.

Como sugere o militante, a compreensão de cultura popular, diferente do passado, é percebida de forma mais ampla. A compreensão de uma cultura "genuína" e "autêntica" não mais existe. Neste contexto, a cultura popular é ressignificada através da possibilidade da mistura, da incorporação de elementos vários que se colam à experiência anterior, transformando-a continuamente; uma concepção herdada, de algum modo, dos movimentos antropofágico e tropicalista, tão importantes na cultura brasileira.

A Bienal conta com a participação de outros grupos juvenis (hip hop, capoeira, grupos circenses, etc.), personalidades e artistas de âmbito nacional, bem como representantes da cultura popular da cidade que a acolhe (poetas populares, grupos folclóricos, etc.), estabelecendo um diálogo com os artistas e a comunidade local. Intitulada de Lado C, a Bienal realiza uma experiência de intercâmbio de saberes entre os participantes do evento e os artistas da comunidade que a sedia. O Lado C atualiza simbolicamente o caráter interventivo do movimento estudantil atravessado

cerces da hipocrisia e do comercialismo estúpido e vulgar. A manipulação da informação, a uniformização, a pasteurização, enfim, a reprodução do mesmo não vem do acaso. Elas existem para apagar os países, afogar a soberania e identidade do povo num mar de lama, podridão e ignorância. Lutamos por uma arte e uma cultura onde não predomine o banal mortal, a esquizofrenia, o miolo mole e a intransigência elitista. Queremos que a arte e a cultura tenham abrigo certo ao invés de serem despejadas. Pela criação de um movimento artístico/cultural em defesa da soberania, da identidade nacional e da cultura popular. Queremos política cultural desenvolvida pelo Estado, que ponha fim ao balcão de negócios em que se transformou o Ministério da Cultura. Pela democratização da produção, do acesso e da difusão da cultura. Todos a $2^{a}$ Bienal da UNE em fevereiro de 2001 no Rio de Janeiro. Ouro Preto, 15 de Julho de 2000.” 
pelo ideário do popular. ${ }^{6}$ Atualiza, de alguma forma, o romantismo revolucionário e a opção dos estudantes por uma luta que inclua a sociedade inteira. Como veremos a seguir, a troca de experiências e saberes é a tônica desta relação que se quer continuada:

Tem também o Lado C, que é esse contato com as comunidades. Em Recife a gente fez contato com uma série de comunidades, geralmente são comunidades carentes que desenvolvem trabalhos culturais absolutamente interessantes, que vem muito baseada na idéia dos CPCs de manter esse contato com as comunidades, mas não tem aquela idéia que tinha nos CPCs que você chegava pra ensinar as pessoas. É o contrário. É mais pra ver o que está acontecendo da produção de lá e provocar algum tipo de encontro, de intercâmbio entre a produção local e a produção não só universitária, mas de artistas. Por exemplo, uma das coisas mais interessantes que tiveram no lado C foi o encontro de Hip Hop em Pernambuco. Porque Pernambuco também tem uma cena de Hip Hop forte. O Gog desenvolve um trabalho super interessante de reggae em São Paulo, em Brasília, e houve um debate entre eles. Foi riquíssimo. Então esse Lado C é importante pra gente conhecer esse trabalho mais periférico, que não está no centro, periférico no sentido de não estar no centro da produção cultural brasileira, mas que é riquíssimo e que talvez seja a grande força da cultura brasileira.

Como já observado, diferentemente dos CPCs, a Bienal tem uma outra perspectiva daquilo que seja um trabalho com a cultura. Esta aparece não mais com o objetivo de "conscientização" do povo, ou seja, como um instrumento pedagógico de formação política. Mais do que "usar" a cultura como meio de transformação das consciências e do próprio meio, a Bienal surge como um espaço de resgate do político que se apresenta disperso nas mais variadas expressões e redes estudantis.

$\mathrm{Na}$ década de 60, os estudantes eram os sujeitos históricos que iriam politizar a sociedade brasileira. No início do milênio, os estudantes dispersos significam a cultura como meio e possibilidade de encontro deles mesmos com seus projetos. Na concretização do encontro, o aparecimento do político e da crítica social. Na manifestação artística os estudantes mostram que "mais do que querer mudar o país, eles querem compreendê-lo".

Como conseqüência da realização das Bienais surgiu a idéia da criação dos CUCAs (Centros Universitários de Cultura e Arte) ${ }^{8}$ que são grupos

\footnotetext{
${ }^{6}$ De fato, o Lado C expressa de modo mais simbólico essa intervenção dos estudantes com as comunidades que, no cotidiano, se afirmará com a realização das atividades dos CUCAs através dos Pontos de Cultura.

${ }^{7}$ Fala do cantor Chico César que participou da $1^{\text {a }}$ Bienal realizada em Salvador, em 1999 (Caderno da Bienal).

${ }^{8}$ A idéia dos CUCAs nasce na $2^{a}$ Bienal realizada no Rio de Janeiro.
} 
autônomos que têm como ponto central o intercâmbio de coletivos artísticos existentes nas universidades e a discussão acerca da cultura local e popular. A idéia do CUCA nasceu de duas críticas colocadas para o movimento estudantil: a) da maneira instrumental que o movimento trata a cultura e; b) da lógica de que fazer cultura é realizar eventos.

Ainda baseada na idéia de articular cultura e militância somente através das Bienais, a UNE não conseguia efetivar um projeto cultural que fosse de grande capilaridade e com certa continuidade. A ausência de um trabalho junto aos grupos culturais existentes nas universidades durante os anos que intercalavam as Bienais não permitia uma continuidade no processo de diálogo do movimento com os grupos de cultura.

Como nos relatam dois dos atuais coordenadores nacionais do CUCA,

$\mathrm{Na}$ verdade, percebeu-se que as Bienais acontecendo de dois em dois anos deixavam um vácuo. Então, para que elas passassem a cada vez mais se saírem melhor e serem mais representativas do ponto de vista dos estudantes que produzem cultura, o CUCA foi criado como centro e circuito - porque o CUCA pode ser tanto centro como circuito de cultura e arte universitária - pra subsidiar as Bienais para que elas tivessem um trabalho mais consistente (Coordenador do CUCA de São Paulo).

Então, a primeira Bienal que foi em Salvador, foi uma primeira experiência para lançar essa idéia do trabalho cultural. Já na segunda a gente sentiu a necessidade de ter um trabalho mais permanente, porque a Bienal é um evento. Então a gente lançou o CUCA: o circuito universitário de cultura e arte mas que também é o centro universitário de cultura e arte. Porque a gente sentiu a necessidade de que não bastava fazer um evento de dois em dois anos; tinha que ter um trabalho no dia a dia das entidades, um trabalho cultural. Por isso que a gente lançou o CUCA (Coordenadora do CUCA de São Paulo).

Com o surgimento dos CUCAs investe-se no modelo inverso: a idéia de priorizar não tanto os eventos, mas o processo realizado pelos diversos grupos artísticos universitários ligados aos CUCAs. Os eventos seriam uma conseqüência da vida desses grupos e a expressão máxima do que é produzido nos mesmos.

A realização de um trabalho cultural por parte da UNE se justifica - com base no relatório do $4^{\circ}$ Seminário Nacional dos CUCAs realizado em São Paulo (novembro/2003) - através de quatro grandes premissas, todas elas articuladas com as idéias chaves implícitas no projeto das Bienais. São elas:

1. [...] a articulação de um amplo movimento, abrangendo diversos setores e organizações culturais, em torno da construção de uma corrente 
de opinião em defesa da cultura brasileira e de sua maior interlocução com os países da América Latina;

2. [...] a de que a predominância de uma visão mercadológica de cultura não só ameaça à sobrevivência de uma autêntica cultura nacional e popular como também sufoca o florescimento de novas manifestações culturais que não estejam inseridas na lógica do mercado. Tal situação afeta especialmente os jovens artistas, muitos dos quais estão entre os mais de três milhões de estudantes universitários brasileiros, sendo a Universidade um importante pólo irradiador de cultura e arte.

3. [...] a possibilidade de as entidades estudantis representarem mais e melhor o conjunto dos estudantes, estabelecendo, através da cultura, um canal privilegiado de interação e intervenção política.

4. [...] a possibilidade concreta que temos de interferir diretamente nas Políticas Públicas de Cultura. Afinal de contas, a predominância de uma visão mercadológica em detrimento da valorização da cultura nacional e popular e a ausência de espaço para jovens artistas está vinculado a (des)política cultural dos últimos anos. A existência de forças comprometidas com a mudança no governo federal abre grandes possibilidades. (Relatório do $4^{\circ}$ Seminário nacional dos CUCAs: 19-20)

Desde a sua criação, em 2001, os CUCAs passaram por diversas etapas de organização, realizando suas discussões e construindo suas redes a partir dos fóruns do movimento estudantil. Na pauta das reuniões, o debate acerca de sua autonomia organizativa e financeira, bem como, sua organização interna (comissões, grupos de trabalho, seminários); sempre levando em consideração a preocupação de "não reproduzir mecanicamente a estrutura organizativa das entidades estudantis" (ibid.: 30).

Ainda em processo de consolidação em algumas universidades, hoje os CUCAs começam a sistematizar sua ação enquanto núcleos de produção cultural. Nesse percurso de fortalecimento, alguns deles foram contemplados pelo Ministério da Cultura com apoio financeiro e logístico para a realização de seus projetos. Este apoio faz parte de um projeto nacional que objetiva fomentar no país vários pontos de cultura. ${ }^{9}$

\footnotetext{
${ }_{9}$ O projeto dos pontos de cultura é uma das tentativas do Ministério da Cultura de construir uma rede horizontal de articulação, recepção e disseminação de iniciativas culturais no país a partir de vários grupos artísticos. Além disso, objetiva promover, ampliar e garantir o acesso aos meios de uso, produção e difusão cultural às diversas experiências que compõem esta rede. Os oito CUCAs contemplados como pontos de cultura são: Campina Grande, Recife, Salvador, Vitória, São Paulo, Rio de Janeiro, Curitiba e Porto Alegre (cf. http://www.une.org.br/cuca).
} 
Com diferentes realidades e níveis de organização, os CUCAs vão formando uma rede de pontos e projetos culturais organizada a partir do espaço do movimento estudantil. As experiências mais estruturadas estão localizadas em oito cidades brasileiras, a saber, Campina Grande, Recife, Salvador, Vitória, Rio de Janeiro, São Paulo, Curitiba e Porto Alegre e possuem projetos de intervenção cultural já definidos.

Mas o que tem de "novo na novidade"? O que tem de político na experiência dos coletivos de cultura e como os mesmos associados às Bienais favorecem a (re)articulação do próprio movimento e o oxigena? $\mathrm{Na}$ tentativa de perceber melhor estas questões, analisaremos a dinâmica e realização de uma destas experiências: a IV Bienal de Arte e Cultura da UNE.

\subsection{Um encontro com nossa América}

Sedeado na cidade de São Paulo e tendo como tema central "Um encontro com nossa América", a IV edição da Bienal de Arte e Cultura da UNE foi realizada juntamente com o XIV Congresso Latino-americano e Caribenho de Estudantes (CLAE) - que analisaremos num outro momento - reunindo estudantes de toda a América Latina, obtendo, pela primeira vez, uma dimensão continental.

Aliando uma conjuntura política internacional favorável a um desejo antigo de desenvolver esta temática, a discussão sobre a realidade e os desafios da integração latino-americana foi o fio condutor dos trabalhos ali realizados.

Com cerca de quatro mil estudantes, a Bienal contou também com a presença de ministros de Estado de vários países (Cuba, Venezuela, Uruguai, Brasil), o que reforça sua capacidade de articulação institucional e sua força enquanto projeto de visibilidade social. Os mesmos debateram a necessidade de estabelecer um intercâmbio maior entre os países, nos campos de educação e cultura, bem como a necessidade de articular projetos comuns. Participaram também personalidades reconhecidas nos mais diversos campos sociais, entre músicos, poetas, escritores, intelectuais, desportistas, etc.

Nesta diversidade de interesses, manifestações e debates, a Bienal acaba por articular redes culturais de diferentes regiões, estilos, vivências e experiências, servindo como um espaço de integração e reconhecimento de grupos existentes nas universidades, bem como, de outros movimentos juvenis de cunho cultural. A interlocução com a cultura hip hop (cada dia mais fortalecida), ${ }^{10}$ com grupos culturais comunitários, desportivos,

\footnotetext{
${ }^{10}$ As Bienais têm sido um grande espaço de divulgação da cultura Hip Hop que, no último ano, percorreu juntamente com a UNE o país inteiro na Caravana de Cultura, que passou por diversas universidades fortalecendo e divulgando os CUCAs.
} 
entre outros, mostra que fica cada dia mais claro para o movimento estudantil a necessidade de diálogo e articulação com outros movimentos juvenis. Isso também fica evidente quando, em sua programação, se realça essa discussão através de temáticas de interesse juvenil como: software livre, música na internet, comportamento juvenil, movimento contra a guerra, entre outros.

Mas, diferentemente da Bienal anterior, marcada por momentos de grande visibilidade e euforia coletiva, ${ }^{11}$ esta foi evidenciada pelo seu inverso: a experiência mais efetiva de troca aconteceu nos pequenos espaços organizados e naqueles mais espontâneos e informais. Os cafés literários, as rodas de samba, a discussão sobre intervenção política e artística, os encontros entre os CUCAs, as oficinas de arte, foram alguns destes espaços que privilegiaram este tipo de experiência. A experiência - vivida a partir destes contatos informais - torna-se o locus de reconhecimento inter-subjetivo privilegiado dos estudantes, onde a dimensão do político também se redimensiona.

É importante realçar que, apesar desses espaços de troca e vivências terem sido marcadamente importante nesta Bienal - os mesmos sempre estiveram presentes nas edições anteriores, sublinhando uma certa dinâmica que privilegia a troca a partir da proximidade, do informal. As dificuldades de última hora na realização de alguns painéis, os imprevistos, uma certa dispersão - característica comum nesses eventos -, a fragmentação de atividades ocasionada pela programação dividida com o CLAE, podem ter colaborado para tal registro.

Todos estes elementos baseados nas micro-relações, na informalidade, são essenciais na construção de identidades, no fortalecimento dos grupos, na formulação de projetos de ação para o futuro. O corte identitário passa aqui através destas relações: da pessoalidade, do lazer, das relações construídas através dos signos que misturam elementos da identidade tanto estudantil quanto juvenil, etc.; diferente da dinâmica e lógica tradicional do movimento estudantil - também legítima - que passa por outras vias e espaços identitários e que produz outras regras e lógicas na ação militante.

A amenização de uma disputa política por parte dos grupos e tendências do movimento estudantil colabora no sentido de aglutinar pessoas dos mais variados setores e grupos para participarem na construção de um projeto cultural comum. Subsume-se a lógica partidária e se visibiliza

${ }_{11}$ Aula Magna de Ariano Suassuna, Mesa final com Gilberto Gil, realização de grandes shows, entre outros. 
a lógica da transversalidade; o que não quer dizer que a idéia da organização das Bienais e dos coletivos de cultura seja aceita da mesma forma e interesse entre todas as tendências do movimento estudantil e que não haja certos tipos de conflito entre elas.

A resistência e a indiferença de algumas delas concorrem na dinâmica de construção deste projeto e, de certa forma, a enfraquece, quando não soma ou a reconhece. De toda forma, existem mais consensos que dissensos.

Bandeiras de luta como o aumento de verbas para a cultura; a formulação de um projeto cultural nacional com uma visão menos mercadológica, mais solidária e comprometida com os grupos culturais; maior apoio à cultura popular, entre outros, são agendas que unificam, que catalisam a participação, a identificação e o apoio dos estudantes.

Essas bandeiras mais específicas da temática cultural não excluem, mas integram, o rol de bandeiras clássicas do movimento estudantil. Estas últimas também foram parte integrante das discussões na Bienal. Entre algumas de destaque estão, a Reforma Universitária, a Assistência Estudantil, o Passe Livre, entre outros.

Este mosaico, que se visualizou através de discussões, espetáculos e manifestações culturais espontâneas, propiciou também momentos significativos, que nos ajudam a entender a dinâmica, a lógica, o ideário deste evento. Neste sentido, pontuaremos dois destes momentos, dois cenários, entendendo-os como elementos importantes de nossa análise.

\section{Cena 1 - Imagem}

As delegações ainda chegavam. Aos poucos, ouviam-se sotaques, expressões, línguas; viam-se cores e aparências diferentes. E por um momento, o espanhol parecia invadir aquele lugar: a Bienal de São Paulo, onde acontecem as grandes exposições de arte moderna no Brasil. Mas para o esperado, o movimento ainda era tímido. Enquanto isso, fui me familiarizando com o espaço: caminhei, conversei com as pessoas, vi o corre-corre dos organizadores e a montagem das obras selecionadas no campo das artes visuais. O espaço parecia ainda em construção, mas já dava mostras do que seria quando finalizado.

Do lado esquerdo de quem entra, um grande mural sendo grafitado. Impressionava seu tamanho, impressionava a grafitagem com seus conteúdos exclusivamente urbanos, a mistura de cores, as colagens de papel misturados à tinta de spray. Constituído de grande fragmentação, o mural evocava críticas ao modelo de uma sociedade consumista, patologizada, bélica e cindida com a natureza. Era também o retrato fiel dos grandes 
centros urbanos, caracterizados pela sua imponente beleza e também degradação; pela sua capacidade de gerar vida e de excluí-la em sua autofagia; pela dispersão e pluralidade social que gera múltiplas identidades, estilos, tribos e ideologias. Tudo ali, registrado na tela-totem, a partir da imaginação de um poeta pintor.

Naquele momento, pensei também que a arte poderia ser um elemento capaz de sugerir reinvenções identitárias. E poderíamos pensar que as distâncias entre a identidade estudantil e juvenil já não eram tão grandes como no passado, onde ser jovem, era ser estudante.

Um pouco à frente do mural, o espaço para os cafés literários, com imagens de Patrícia Galvão, a Pagu, escritora modernista do início do século passado. Um espaço simples: uma pequena mesa para os debatedores e um grande tablado circular permeado de almofadas. Nos dias seguintes, esse espaço se transformaria num lugar onde as pessoas - sentadas, deitadas, em pé - discutiriam diferentes assuntos relacionados à escrita e à literatura.

Saindo do lado esquerdo da Bienal fui caminhando para seu centro, onde assisti a montagem dos vários stands comerciais e de divulgação de material estudantil dos vários países da América Latina ali representados. Era também o espaço do balcão de informações do evento; da entrada dos participantes que teimavam em chegar com disposição apesar do cansaço de suas viagens; da exposição para venda de camisas, colares, pulseiras e artigos regionais.

Aqui - e neste espaço cultural em particular - a estética, o visual, se colocam como fundamentais no processo de comunicação. Como aponta Pais, "a estetização do corpo arrasta uma expressividade que é fonte de reconhecimento e integração grupal. A aparência é causa e efeito de uma intensificação da atividade comunicacional, a partir da qual se revelam territórios de pertença, estéticas inclusivas ou exclusivas" (2004: 29). Estética que usa o corpo, o espaço, o imaginário. Estética que - neste espaço se alia a um imaginário profundamente marcado por signos de cunho político e social. Estética que gera estilos; estilos que incorporam ideários; ideários traduzidos através de estetização da política e de uma politização da estética.

Continuando o caminho e me dirigindo para o lado direito, percebo a existência de dois espaços: um para a realização de oficinas e outro para a Mostra de Artes Visuais, que desta vez homenageou a arquiteta Lina Bo Bardi. A Mostra, que era constituída por trabalhos produzidos por vários universitários-artistas contemporâneos, se dividia em três eixos: a) obras bidimensionais (pinturas, fotografias, gravuras, desenhos, etc.); 
b) obras tridimensionais (esculturas e objetos); e c) instalações. E apesar de a Bienal não condicionar a participação dos artistas à atuação numa arte engajada, muitas das obras possuíam esse caráter. A crítica ao racismo, à visão de uma educação voltada para o mercado, ao reinado das marcas e à interferência das multinacionais na vida das pessoas e do ambiente, à violência, foram algumas das temáticas observadas.

Meu percurso, sem muita direção, lógica ou compromisso, talvez refletisse um pouco o caráter desterritorializado daquele espaço. E apesar de concentrado, o que permitia a movimentação sem muitas dificuldades, meu percurso parecia visualizar várias paisagens, portas de entrada e saída para diversos mundos que, com suas fronteiras e demarcações, dialogavam entre si sugerindo possibilidades de decodificação das linguagens ali apresentadas. Aqui compreendemos o quão importante são os elementos da imagem, do visual, da estética do espaço, na definição, no conceito. O espaço também se constitui mensagem, conteúdo, elemento da lógica e da racionalidade dos objetivos da Bienal. Espaço este que se impõe com seu conteúdo-mensagem, mas também como um espaço a ser construído, transformado, a partir da intervenção dos estudantes ali presentes.

$\mathrm{Na}$ continuação da caminhada de experimentação do espaço, o elemento da surpresa. Ao longe, observo uma multidão que se aglutina e um som que se aproxima, aos poucos. Era o som do maracatú cearense do grupo "Brincantes Cordão do Caruá" que chamava a atenção dos participantes e os animava. Era a presença dos grupos de cultura popular que começava a se manifestar. $E$ as diferentes dimensões da arte ali expressas se inter-cruzavam: cultura popular com arte de rua; a cantoria dos cantadores com a música dos rappers; o estilo e estética das indumentárias regionais, características da tradição popular e as linhas e cores da grafitagem dos novos pintores urbanos, ao fundo. Momentos de encontro, momentos de síntese, onde o elemento que separa é também o que une, revelando e dando visibilidade a uma grande mestiçagem cultural, colorida e construída pelos diversos atores ali presentes.

Logo, brasileiros, uruguaios, mexicanos, argentinos, chilenos, equatorianos, venezuelanos, haitianos e tantos outros se confraternizavam. Uma grande roda foi feita e, sem combinar, os estudantes faziam um cordão com as bandeiras dos diferentes países. A performatividade que gera êxtase, alegria e uma identificação inter-subjetiva serve de pretexto para transitar no imaginário latino-americano. Surgem os gritos de guerra de cada país, seus símbolos identitários, mas e principalmente, a idéia de uma latino-americanidade. E, de modo simples e simbólico, o tema do 
evento era desenvolvido: a integração latino-americana através da arte e da cultura, fazendo um contraponto à idéia de integração realizada exclusivamente no espaço do mercado. Os estudantes, a idéia de coletividade, a arte como um dos instrumentos do fazer político, o espaço. Tudo ali. E pareceu-me que, naquele momento, foi iniciada a Bienal.

\section{Cena 2 - Som}

A sala estava cheia e todos queriam os melhores lugares. Era dia de encerramento da IV Bienal e do XIV CLAE; era dia de ver Aleída Guevara (filha do Che) - que dissertaria sobre o papel da juventude -, de assistir Capinam, que faria uma fala simbólica de encerramento do encontro e Gilberto Gil que, como ministro, debateria a participação do Brasil em um efetivo processo de integração latino-americana através do viés da cultura.

Bandeiras, gritos e palavras de ordem animavam os estudantes que, ansiosos, esperavam o momento. Os rituais de identificação coletiva, uma certa catarse e euforia característica das multidões, se faziam evidentes.

A presença de bandeiras e slogans partidários, de um ideário classista de sociedade, de um certo anti-americanismo baseado na idéia da formação de um bloco latino-americano e do culto a líderes políticos como Fidel, Chavez e Lula também ali se manifestaram, marcadamente. A co-realização da Bienal com o CLAE e a presença das personalidades já mencionadas, certamente, favoreceram no aparecimento destas manifestações.

Com um certo tempo de atraso inicia-se o encerramento dos dois encontros. Num primeiro momento, a parte formal: posse da nova diretoria da OCLAE, avaliação do encontro, discurso de representantes estudantis. Num segundo momento, a presença e as falas simbólicas de Aleída Guevara, Capinam e Gil.

Aleída discursa sobre o papel do jovem frente aos desafios de um mundo globalizado. Sua figura carismática, aliada ao fato de ser filha do Che, são elementos importantes do imaginário político juvenil que servem como pontos catalisadores de mobilização. Sala cheia e muita curiosidade. Já sua concepção de juventude e ação política relatada por ela mesma parece conter uma conceituação fortemente fechada. O jovem é... O jovem deve... O jovem político por natureza... Enfim! Um discurso impositivo, com ótica de adulto, que naturaliza o papel do jovem - sem compreender ou perceber que esta categoria, como lembra Bourdieu (1983) pode ser esvaziada se não se apropriar das diversas realidades juvenis existentes -; um discurso de quem aprendeu ser assim, numa determinada época contextualizada por seus variados fatores e não a re-significou. 
No meio de sua exposição, burburinho. Acabava de chegar Gilberto Gil. A exposição é interrompida por alguns minutos para que fosse anunciada sua presença. Não era preciso. Um pouco mais e termina a fala de Aleída.

Gil fala, discursa, é aplaudido. Os estudantes pedem que ele cante. Ele canta. Com Capinam e ao lado de Aleída, Gil canta "Soy loco por ti América". Os compositores e a filha do homenageado da música. Era o que todos queriam ouvir. Gritos, aplausos, vozes, coro. Parece existir um magnetismo que amalgama o desejo militante daquelas pessoas. $\mathrm{O}$ mesmo magnetismo das multidões que Le Bon já estudava no final do século XIX. O resgate dos símbolos da América Latina: as bandeiras, a música, os ícones, o imaginário político partilhado num só espaço por uma multidão. $\mathrm{O}$ retorno do passado para re-significar o presente? Talvez! A mística que alimenta a militância, tão em voga ultimamente? Talvez! Um espaço, definitivamente em suspenso, onde o que fazia sentido era estar ali, naquele momento.

Soy loco por ti, América, soy loco por ti de amores. Era o refrão que resgatava um certo romantismo revolucionário ${ }^{12}$, o mesmo romantismo que tanto Löwy e Sayre (1995) quanto Ridenti (2000) identificam na ação dos estudantes dos anos 60, com todo o ideário pautado na construção de um homem novo, este, idealizado no homem do povo. Um ideário romântico hoje resgatado, de outra forma, pelos movimentos altermundistas.

E o poeta já tinha profetizado: "El nombre del hombre muerto ya no se puede decirlo, quién sabe? Antes que o dia arrebente, antes que o dia arrebente. El nombre del hombre muerto antes que a definitiva noite se espalhe em Latinoamérica. El nombre del hombre es pueblo, el nombre del hombre es pueblo".

E antes que o dia arrebente, Gil cantou "Punk da periferia" e a Bienal foi encerrada.

\section{A construção do mosaico: fragmentação, cotidianidade e política}

As duas cenas acima descritas são exemplos do grande mosaico da Bienal. Um mosaico que, em sua fragmentação e descontinuidade inerentes, expressa um conteúdo desenhado a partir do cotidiano, da partilha de experiências, do fazer coletivo dos vários estudantes ali presentes.

\footnotetext{
${ }_{12}$ Para Ridenti (2000: 25), o romantismo revolucionário buscava "no passado elementos que permitiriam uma alternativa de modernização da sociedade que não implicasse a desumanização, o consumismo, o império do fetichismo da mercadoria e do dinheiro. Não se tratava de propor a mera condenação moral das cidades e a volta ao campo - a superação da modernidade capitalista cristalizada nas cidades, tidas no final dos anos 60 como túmulos revolucionários, na expressão do teórico guevarista francês Régis Debray.”
} 
No mosaico, as peças interligam-se a partir de uma estética onde são privilegiadas a fragmentação do desenho; a quase visibilidade da massa que amalgama as peças disformes e não padronizadas; a não preocupação com a perfeição, sugerida algumas vezes, pela própria deformação da imagem desenhada, como num mosaico-mural.

Estes elementos não são apenas características de uma forma e um estilo artístico, mas já são em si, pontos constituintes do conteúdo que se quer mostrar, sugerir. Como se fossem importantes, quase que indispensáveis, mostrar o desenho em todas as suas dimensões, por dentro e por fora, o que deve ser visível no seu todo, mas também o que está latente, pujante, como a massa que une as pedras-peças que constituem a matéria-prima do mosaico-mural.

E se, geralmente, o conteúdo dos mosaicos expressa a visão do artista acerca do cotidiano, é essa mesma cotidianidade - aqui expressa através das diferentes experiências dos militantes estudantis que se interessam pela área cultural e/ou participam dos coletivos de cultura - que constitui o grande cenário-mural da Bienal.

As diferentes experiências acerca daquilo que os identifica em termos de atuação política e cultural; as maneiras diversificadas de se partilhar e interiorizar um imaginário político que pode se traduzir numa identidade coletiva; a construção de redes sociais que, ao costurar e ligar os diversos pontos da rede, potencializam ações e interferências, ora de modo mais latente, ora de modo mais visível; todas estas ações se misturam, se interligam, se completam, se tocam, se unificam, de maneira a potencializar experiências novas, a construir diálogos até então não realizados, experimentações que coloquem no limite as fronteiras demarcadas pelas dimensões da política e da cultura, transformando talvez, o romantismo revolucionário dos anos 60 em realismo comunitário do início do milênio.

Neste sentido, o cotidiano retratado no mosaico se constitui de experiências e ações no campo da política e da cultura como manifestações de um fazer coletivo que se fortalece entre os estudantes. Este fazer torna-se um desafio, na medida em que, neste campo, tudo ainda estar por se fazer, por se inventar. Se temos os CPCs da UNE como inspiração, não podemos tê-lo como modelo, visto as grandes diferenças contextuais em que foi realizada esta experiência. O grande desafio hoje é saber comunicar para as pessoas diante de uma sociedade de massas, de uma sociedade do espetáculo (Debord, 1992).

Como afirmam Alvarez, Dagnino e Escobar (2000), "os movimentos sociais são uma arena crucial para a compreensão de como esse entrelaçamento, talvez precário, mas vital, do cultural e do político ocorre na prática". 
Neste espaço, onde cultura e política se inter-comunicam e são faces de uma mesma moeda, torna-se importante recuperar os elementos que unem essas dimensões. Qual a massa que amalgama as peças do mosaico? O que articula essas esferas - política e cultura - na militância política destes estudantes? Qual a visão de cultura que se transpõe e se cola no fazer político dos militantes estudantis que participam destes coletivos?

No artigo "Cultura e Política nos movimentos sociais latino-americanos” (Alvarez, Dagnino e Escobar, 2000), os autores desenvolvem alguns conceitos que podem nos ajudar a perceber como os movimentos sociais na América Latina articulam em suas práticas essas duas esferas. Neste sentido, aproximam duas categorias (política cultural e cultura política) na tentativa de - mais que definir as fronteiras e limites de um e outro mostrar que as mesmas são complementares e interdependentes.

Além disso, enfatizam a ação dos movimentos sociais como agentes de transformação e mudança da cultura política dominante, a partir do que eles denominam de política cultural. Esta última, não entendida como "ações do Estado ou de outras instituições com relação à cultura, considerada um terreno específico e separado da política, muito frequentemente reduzido à produção e consumo de bens culturais" (Alvarez, Dagnino e Escobar, 2000:11), mas "ao processo pelo qual o cultural se torna fato político" (ibid.).

No rol de exemplos estão vários dos movimentos sociais que, ao conceberem outras formas de ação política e ao se apropriarem de outras compreensões do mundo da vida, redefinem o poder social e a concepção do que é político. A manifestação de movimentos juvenis que - ao proporem a ação direta como intervenção visando uma democracia mais participativa - questionam a política e a democracia fortemente representativa; o movimento feminista, ao considerar importante a redefinição do uso da palavra e do léxico na reconfiguração do imaginário social, marcadamente, masculino; entre outros, são alguns dos exemplos de práticas da política cultural dos movimentos sociais.

Nesta perspectiva, importante seria indagar se os coletivos de cultura não estariam promovendo no interior do movimento estudantil, políticas culturais que, de certa forma, redimensionam as práticas de representação política do próprio movimento, marcadamente tradicionais em termos de agir político.

\section{Reflexões iniciais sobre a política cultural do movimento}

Numa perspectiva de temporalidade, percebemos a Bienal de São Paulo como um espaço em que estudantes e artistas puderam (re)afirmar e fortalecer a proposta de um projeto político cultural que - sempre em "processo 
de acabamento" - precisa ser divulgado e assumido no interior do próprio movimento estudantil e nas universidades.

Neste sentido, importante se faz aprofundar os laços entre os coletivos de cultura e as entidades estudantis. A presença do diálogo e da negociação entre os mesmos serão essenciais para a continuidade deste projeto. A fragilidade desta relação - mesmo que mais visível no início desta experiência - ainda pode ser observada em vários momentos. A ausência de parte expressiva de militantes de outras tendências do movimento estudantil na $4^{a}$ edição da Bienal - que por possuírem uma perspectiva de trabalho cultural diferenciada (tanto na forma quanto no conteúdo) e por projetarem nesta suas diferenças políticas -, é um exemplo.

Estas reflexões também advêm da percepção de que, apesar da razoável participação de estudantes nas Bienais já realizadas, as mesmas ainda não conseguem catalisar ou qualificar essa energia participativa dos mesmos numa ação contínua de pós evento. E apesar de os CUCAs terem surgido com esta compreensão, ainda não conseguiram empreender uma força suficientemente capaz de se tornar presente no imaginário dos estudantes enquanto uma outra forma/alternativa de ação política dentro do movimento. A maior visibilidade dos CUCAs ainda se dá com a realização das Bienais.

A aproximação dos coletivos de cultura com as entidades e as variadas tendências do movimento pode facilitar seu processo de fortalecimento no interior das universidades nos diferentes estados, pois apesar de os coletivos terem visibilidade em alguns pontos do país, ainda são organicamente frágeis. As entidades, com sua estrutura organizacional, podem dar maior visibilidade aos coletivos. Além disso, os pontos de cultura e a interlocução com o Ministério da Cultura (MinC) podem ser outra alternativa no sentido de consolidar essa proposta de intervenção político-cultural.

Por outro lado, a aproximação das entidades com os coletivos de cultura pode facilitar o processo de comunicação destas mesmas entidades com a grande maioria dos estudantes que - muitas vezes - não se vêem representados com a linguagem política-institucional clássica.

Para isso, faz-se também importante que alguns conflitos devam ser relativizados ou resolvidos: a desconfiança entre os grupos políticos, a falta de uma maior participação das tendências do movimento que queiram se integrar ao processo de concepção e realização das Bienais, entre outros.

Como observa um dos militantes que participa dos CUCAs,

O contato da UNE com o CUCA tem sido muito bacana porque você vê um diretor de cultura da UNE dizendo: "Pô, isso aí é uma instalação, né?". Entendeu? O cara 
chegar e dizer: "não rapaz, eu defendo é o pós-modernismo". Antes o cara não sabia a diferença de um Picasso pra um Da Vinci. Acabam saindo com mais sensibilidades. Isso é importante pra eles. Como é também praquele cara da cultura por sair mais politizado. Eu acho que essa é a relação bacana.

E apesar dos coletivos de cultura e da própria Bienal não pautarem sua atuação baseada na lógica das tendências e correntes partidárias, a participação de um maior número de grupos na organização e estruturação tanto dos CUCAs como das Bienais, faz-se importante no sentido de comprometê-los, de maneira mais efetiva, com o projeto cultural. Além disso, realça a pluralidade de diferenças existentes no movimento, dinamizando-o.

Neste sentido, é importante também que a aproximação se faça sem resistências. A resistência no interior do movimento em relação aos coletivos de cultura deve-se, em parte, pelo fato de estes proporem outra lógica e dinâmica de intervenção estudantil. Como já destacamos, o movimento, identificado com uma lógica de participação mais institucionalizada e amparado numa ação política mais tradicional, tende a não assumi-los totalmente como prioritários no seu campo de ação.

Aqui, retomamos a idéia de Melucci acerca da necessidade de desnaturalizar a tendência hegemônica existente tanto no senso comum, quanto em muitas análises correntes sobre os fenômenos contemporâneos de ação coletiva que é a idéia de unicidade dos movimentos sociais.

Essa desconstrução faz-se necessária no sentido de, ao visualizar as diferentes expressões, formas de organização, modelos de linguagem, etc., num determinado movimento social, compreender e perceber melhor a dinâmica que proporciona a existência de suas ações, tomadas de posição, discursos, entre outros.

Certamente, os coletivos de cultura aqui estudados se inserem como uma das expressões do movimento estudantil. Estes - a partir de seus processos de mobilização, formas de organização e fortalecimento enquanto ator coletivo - devem negociar suas pautas e interesses com os outros coletivos e tendências do movimento, gerando assim uma dinâmica que possibilite a concretização de seus objetivos. Mais que unidade do movimento social, existe uma unidade de ação.

Ainda pensando na ação dos coletivos de cultura, queremos ressaltar algumas de suas diferenças no que remete à temporalidade da ação dos estudantes. Ou seja, queremos destacar diferenças existentes que se estabelecem nas práticas dos estudantes dos anos 60 e dos atuais militantes no que concerne ao seu fazer político e cultural. 
Isso se torna pertinente na medida em que compreendemos os atuais coletivos como herdeiros de uma tradição do movimento estudantil que alia cultura à participação, arte à política. Compreendendo que a linha que diferencia a arte e a política nesses movimentos é sempre muito tênue, não queremos aqui analisar o papel de cada uma delas na intervenção dos antigos estudantes e os atuais.

A questão que se coloca é outra e se refere ao foco de atuação do movimento frente às demandas estudantis. E aqui, descobrimos que, se antes o foco dos movimentos de cultura no interior do movimento estudantil se dava a partir do pólo cultura-para-chegar-à-politica, hoje o acento se dá no pólo política-para-chegar-à-cultura. ${ }^{13}$ Se nos anos 60 a experiência dos CPCs se concentrava na política ("instrumentalizada" pela cultura), os CUCAs se concentram na cultura ("instrumentalizada" pela política).

Isso fica perceptível quando, indagando os militantes dos CUCAs acerca das bandeiras do movimento estudantil clássico que tem ressonância nos coletivos de cultura, as respostas dos mesmos se concentram nas questões de política cultural como, maior verba para a cultura (luta do movimento por $1,5 \%$ do PIB para a cultura), o projeto da Agência Nacional do Cinema e Audiovisual (ANCINAV), entre outros. As entidades estudantis são percebidas como aliadas das lutas dos coletivos de cultura quando delas se apropriam. A luta pelo aumento de verba para os movimentos culturais no Brasil foi incorporada às lutas do movimento estudantil clássico e, portanto, tem ressonância dentro dos CUCAs. As bandeiras de cunho exclusivamente político - como por exemplo, a Reforma Universitária - são citadas, porém, ficam secundarizadas frente a estas outras.

Este posicionamento pode ser melhor compreendido se observarmos que a maioria dos estudantes que participam dos coletivos de cultura, ou estão ligados a este campo, ou priorizam o mesmo como uma forma de atuação por não se identificarem com as formas tradicionais de participação política, percebida por boa parte dos estudantes, como negativa, ou seja, ancorada em visões negativas da política, desgastada pela atuação de seus representantes, que não tem conseguido dar respostas às suas demandas.

\footnotetext{
${ }_{13}$ Isso não quer dizer, no entanto, que os militantes não percebam que o cultural não seja político; ou que tomam as duas dimensões como se fossem separadas. O que queremos afirmar é que hoje, diferentemente dos anos 60 , os militantes que trabalham com os coletivos citados concentram suas ações no campo cultural, sem necessariamente terem a pretensão de mudar os rumos políticos do país. A perspectiva de mudança do país existe, mas se dá noutro nível: na luta pela valorização da cultura, tendo-a como fundamental para o crescimento e soberania do país. Para isto, vê e atua no campo da política institucional de forma a estabelecer um maior número de interlocutores para fortalecer suas lutas.
} 
A atuação no campo da política cultural, desta forma, tem sido um campo cada vez mais aberto para os estudantes que, ao serem impelidos à militância nesta área, percebem sua importância e a sua extrema carência. Além disso, centram-se nesse campo para atuar politicamente. A política se constrói a partir da intervenção na cultura.

Mas se observamos, que o campo da cultura pode ser ressignificado como um espaço para a atuação política, ele também pode ser utilizado numa perspectiva conservadora de tecnização da política, concebendo-a como espetáculo e esvaziando seu conteúdo. Numa sociedade em que o visual e a imagem são tomados como importantes elos na comunicação, a política se estetiza (Benjamin, 1968) no intuito de atrair e envolver "espectadores". Neste sentido, a cultura é apropriada como mais um instrumento de convencimento. As Bienais de Cultura e os CUCAs devem ter o cuidado para não caírem nessa ambigüidade - que algumas vezes se torna latente no seu interior. Reforçar o pêndulo na direção da tecnização da política seria acabar com uma experiência que - com todas as dificuldades - tem tido uma boa aceitação por parte dos estudantes.

Possibilitar a existência de espaços onde surjam outras possibilidades de atuação no interior do movimento estudantil que recuperem o sentido da política entendida como emancipação social e crítica ao instituído (Sousa, 2003), se faz fundamental para a revitalização das entidades estudantis enquanto movimento. O campo cultural emerge de maneira expressiva como uma demanda privilegiada dos estudantes que, ao escolherem enquanto espaço de militância não querem apenas reproduzir lógicas tradicionais da política mas reinventá-las através dos elementos que a arte possibilita. Além disso, surge como uma importante faceta no processo de diversificação da identidade coletiva do movimento que acaba por atrair os estudantes que estavam dispersos em seus cotidianos suspensos da política tradicional. Nesses coletivos fica evidente a percepção de que outras dimensões da política devem ser "energizadas" e fortalecidas enquanto espaços outros de intervenção por parte dos estudantes.

\section{Referências bibliográficas}

Alexander, Jeffrey (1987), "O novo movimento teórico", Revista Brasileira de Ciências Sociais, 2(4), 5-28.

Alvarez, S.; Dagnino, E.; Escobar, A. (2000), "O cultural e o político nos movimentos sociais latino-americanos", in S. Alvarez; E. Dagnino; A. Escobar, A. (orgs.), Cultura e Politica nos movimentos sociais latino-americanos. Novas leituras. Belo Horizonte: Ed. UFMG, 15-57. 
Benjamin, Walter (1968), “A obra de arte na época de sua reprodutibilidade técnica”, Revista Civilização Brasileira, 19/20.

Bourdieu, Pierre (1983), Questões de sociologia. Rio de Janeiro: Editora Marco Zero. Debord, Guy (1992), A sociedade do espetáculo. Rio de Janeiro: Contraponto.

Gohn, Maria da Glória (1997), Teoria dos movimentos sociais: paradigmas clássicos e contemporâneos. São Paulo: Edições Loyola.

Johnston, H.; Laraña, E.; Gusfield, J. (1994), “Identidades, ideologias y vida cotidiana en los nuevos movimientos sociales”, in Enrique Laraña; Joseph Gusfield (orgs.), Los nuevos movimientos sociales: de la ideología a la identidad. Madrid. Centro de Investigaciones Sociológicas, 3-42.

Klandermans, B. (1994), "La construcción social de la protesta y los campos pluriorganizativos”, in Enrique Laraña; Joseph Gusfield (orgs.), Los nuevos movimientos sociales: de la ideología a la identidad. Madrid. Centro de Investigaciones Sociológicas, 183-220.

Laraña, Enrique (1999), La construcción de los movimientos sociales. Madrid. Alianza Editorial.

Löwy, Michael; Sayre, Robert (1995), Revolta e melancolia - o romantismo na contramão da modernidade. Petrópolis: Vozes.

McAdam, Doug (1994), "Cultura y movimientos sociales: de la ideología a la identidad", in Enrique Laraña; Joseph Gusfield (orgs.), Los nuevos movimientos sociales: de la ideología a la identidad. Madrid: Centro de Investigaciones Sociológicas, 43-68.

Melucci, Alberto (1989), Nomads of the Present. Philadelphia. Temple UP.

Melucci, Alberto (1996), Challenging Codes. Collective Action in the Information Age. Cambridge. Cambridge UP.

Melucci, Alberto (1999), Acción colectiva, vida cotidiana y democracia. México: Centro de Estudos Sociológicos.

Melucci, Alberto (2001), A invenção do presente: movimentos sociais nas sociedades complexas. Petrópolis: Vozes.

Mesquita, Marcos Ribeiro (2001), Juventude e movimento estudantil: o velho e o novo na militância. Florianópolis: Universidade Federal de Santa Catarina (diss. de mestrado).

Mesquita, Marcos Ribeiro (2003), "Juventude e movimento estudantil: discutindo as práticas militantes”, Revista Psicologia Política, 3(5), 89-120.

Pais, José Machado (2004), "Jovens, bandas musicais e revivalismos tribais", in J. M. Pais; Leila Maria Blass (orgs.), Tribos urbanas: produção artística e identidade. Lisboa. Instituto de Ciências Sociais.

Ridenti, Marcelo (2000), Em busca do povo brasileiro: artistas da revolução, do CPC à era da TV. Rio de Janeiro: Record.

Sandoval, S. A. M. (2001), "The Crisis of the Brazil Labor Movement and the Emergence of the Alternative Forms of Working-Class in the 1990s", Revista Psicologia Politica, $1(1), 173-195$. 
Sousa, J. T. P. de (2003), “As insurgências juvenis e as novas narrativas políticas contra o instituído”, Cadernos de Pesquisa, 32.

Touraine, Alain (1999) - Podemos viver juntos? Petrópolis: Vozes.

\section{Consulta na Internet}

União Nacional dos Estudantes, Carta de Ouro Preto. Acesso em 15 de setembro de 2000. www.une.org.br

CUCA-UNE, Os pontos de cultura e a UNE. Acesso em 10 de novembro de 2004. http://www.une.org.br/cuca/

\section{Documentos e publicações estudantis}

Relatório do $4^{\circ}$ Encontro Nacional dos CUCAs. São Paulo. 2003.

Revista Especial sobre a $1^{\text {a }}$ Bienal de Cultura da UNE. 1999. 